\title{
Profile of the adverse drug reactions among the multidrug resistant tuberculosis patients treated at a tertiary level hospital in southern India
}

\author{
Basavaraj Sangolli ${ }^{1}$, Rashmi B. M. ${ }^{2, *}$, Basavaraj Savadi ${ }^{3}$, Shruti Ghodageri $^{4}$, Sreeharsha $^{5}$ \\ ${ }^{1-3}$ Assistant Professor, ${ }^{1}$ Dept. of Respiratory Medicine, ${ }^{2}$ Dept. of Community Medicine, ${ }^{3}$ Dept. of Biochemistry, ${ }^{4}$ Senior Resident, \\ Dept. of Anaesthesia, ${ }^{1-4}$ Basaveshwara Medical College \& Hospital, Chitradurga, Karnataka, ${ }^{5}$ Medical Officer-MC, RNTCP, \\ India
}

*Corresponding Author:

Email: dr.rashmi.bgm@gmail.com

\begin{abstract}
Background: The prevalence of multi-drug resistant tuberculosis (MDR-TB) is increasing worldwide. The treatment of MDRTB is challenging due to its delayed diagnosis, prolonged duration of therapy with larger number of drugs, coupled with their great potential for adverse drug reactions (ADRs), which severely impair treatment adherence. Early identification and effective management of ADRs form the cornerstone to ensure treatment adherence, which is an essential aspect in better treatment outcome.

Materials and Methods: A prospective observational study was conducted for a period of 3 years, at Basaveshwara Medical College and Hospital, Chitradurga. All MDR-TB patients who fulfilled study criteria were included in study. After pre-treatment clinical evaluation, necessary radiological, serological and bacteriological investigations, patients were treated by Cat IV regimen for MDR TB and monitored for development of ADRs and treated appropriately.

Results: Mean age of patients was $38 \pm 3.6$ years. A $70.9 \%$ of patients had low body mass index (BMI). A $74.5 \%$ of patients got successfully cured. ADRs were reported among $52.6 \%$ of patients. GI intolerance (49.1\% in intensive phase) and psychiatric symptoms (41.8\% in continuation phase) were most common ADRs reported. Low BMI was found to be significantly associated with ADRs.

Conclusion: Meticulous and regular follow-ups with emphasis on early detection of ADRs during the course of ATT, dosage adjustments to effectively manage ADRs, addressing problem of malnutrition, a compulsory psychiatrist opinion as part of pretreatment evaluation and also during continuation phase of ATT to detect the emergence of psychiatric symptoms, will go a long way in achieving high rates of favourable outcomes among MDR-TB patients.
\end{abstract}

Keywords: Adverse drug reactions; Depression; Suicidal tendencies; Malnutrition; Gastro-intestinal intolerance.

\section{Introduction}

Tuberculosis is a major global public health crisis. India accounts for nearly a quarter of global tuberculosis (TB) burden with reported incidence of 2.8 million cases in 2015[1-3]. The TB control is destabilized by the emergence and spread of multidrug resistant tuberculosis (MDR TB), the disease which is caused by strains of Mycobacterium tuberculosis that are resistant to treatment with at least isoniazid $(\mathrm{H})$ and rifampicin (R)[3-6]. Worldwide prevalence of MDR TB is on a rise, both among new and previously-treated TB cases with a 6 lakh incident cases of MDR/RR-TB reported in 2016[3,4,7,8]. India comprised of second largest number of drug resistant cases with about 1.3 lakh incident cases emerging annually $[4,8-10]$.

Scientific literature has shown that the higher number of antitubercular drugs used in the DRTB treatment, higher rates of adverse drug reactions (ADRs) associated with the second line antitubercular drugs (SLDs) and the prolonged duration of treatment are severely impairing the treatment adherence, thereby significantly impeding the effective management of DRTB[6,11]. Hence, the measures such as early identification and timely, effective management of ADRs, along with patient education and counselling regarding MDR-TB treatment are required to ensure the adherence to treatment, which is a crucial aspect in successful treatment outcome[6,10-12]. With this background, the present study was conducted at a tertiary level teaching hospital in Chitradurga situated in southern India, with the following objectives: a) to understand the profile of adverse drug reactions encountered among the drug resistant TB patients treated at this hospital. b) To study the association of co-morbidities with adverse drug reactions among them.

\section{Material and Methods}

A prospective observational study was conducted for a period of 3 years (Jan 2015- June 2018), at the Basaveshwara Medical College and Hospital, after obtaining ethical clearance from institutional ethics committee. All the patients who were either retreatment cases at diagnosis, failures of new TB cases, any smear positive persons during follow up, contacts of confirmed DR-TB cases, and HIV associated TB cases at diagnosis, were tested on CBNAAT, as per Criteria $\mathrm{C}$ of MDR suspect criteria of PMDT (Programmatic Management of Drug Resistant TB) 2012 guidelines[10]. The patients, who were positive for MTB and were found to be having rifampicin resistance, were further evaluated at the DRTB centre situated in this hospital. Few of them were subjected to culture and drug sensitivity testing (CDST) for ' $\mathrm{R}$ ' and 
'H', as per guidelines[10]. The patients were included in the study after explaining the purpose of the study and obtaining their informed consent. Pregnant women, patients having concurrent major psychiatric illnesses, HIV sero-positive cases were excluded from the study. Persons diagnosed with extra-pulmonary TB were excluded because their drug regimen, treatment duration and outcomes vary depending on the site of the disease.

A pre-treatment detailed clinical evaluation of MDR-TB patients was conducted as per the specified RNTCP guidelines post admission in this hospital[10]. History of any mental illness, drug/alcohol abuse and anthropometric measurements were recorded. Patients were classified on basis of their BMI, according to revised guidelines of grades of obesity for Asians[2]. Patients were subjected to necessary radiological, serological, bacteriological investigations. Additional laboratory tests such as thyroid, renal and hepatic function tests and complete blood counts, blood sugar levels estimation were done. Urine pregnancy test was done for females (in reproductive age). HIV testing by enzyme linked immunosorbent assay was done after pre-test counselling and informed consent. DRTB committee of the hospital approved the initiation of the conventional regimen of 24-27 months (Cat IV) for MDR/RR TB, which was duly started for all these MDR TB patients and they were monitored and observed for the development of adverse drug reactions(ADRs) and treated appropriately as per RNTCP guidelines[1].

The Category IV regimen comprised of 6 drugs Kanamycin, Levofloxacin, Ethionamide, Pyrazinamide,
Ethambutol and Cycloserine during 6-9 months of the Intensive Phase and 4 drugs: Levofloxacin, Ethionamide, Ethambutol and Cycloserine during the 18 months of the Continuation Phase. Special adjustments to the standard Regimen for MDR TB were also done whenever necessary as per the PMDT guidelines[1]. Pyridoxine was administered to all patients on regimen for MDR TB. The dosages of the drugs were decided depending on the weight of the patients.

Out of the total 57 MDR TB patients treated in the hospital during the study period, 2 patients were HIV seropositive cases and 55 patients fulfilled the study criteria and were included in the study. All the patients have completed the treatment except for 3 patients who are in the last 3 months of their antitubercular therapy.

\section{Statistical analysis}

All the characteristics are summarized descriptively. For continuous variables, the summary statistics of $\mathrm{N}$, mean, standard deviation about the arithmetic mean were used. For categorical data, the number and percentages were used and for continuous variables, the summary statistics of $\mathrm{N}$, mean, standard deviation about the arithmetic mean were used. Chi square test was applied to test the significance of association of categorical variables and the associations with $\mathrm{p}$ value of less than 0.05 were considered to be statistically significant. Data was compiled in Microsoft excel spread sheets and analyzed using SPSS for windows version 16.0.

\section{Results}

Table 1: Clinical and treatment characteristics of patients

\begin{tabular}{|l|l|c|}
\hline \multicolumn{1}{|c|}{ Patient Characteristics } & \multicolumn{1}{c|}{ Groups } & $\begin{array}{c}\text { Frequency n(\%) } \\
\mathbf{N = 5 5}\end{array}$ \\
\hline Age Mean years (mean \pm SD) & & $40 \pm 3.6$ years \\
\hline \multirow{2}{*}{ Sex } & Male & $44(80.0 \%)$ \\
\cline { 2 - 3 } & Female & $11(20.0 \%)$ \\
\hline Weight $(\mathrm{Kg})($ mean \pm SD) & & $41.9 \pm 8.5 \mathrm{Kg}$ \\
\hline \multirow{2}{*}{$\begin{array}{l}\text { Grades of obesity according the } \\
\text { Body mass index }\end{array}$} & Under weight $(<18.5)$ & $39(70.9 \%)$ \\
\cline { 2 - 3 } & Normal $(18.5-23)$ & $13(22.8 \%)$ \\
\cline { 2 - 3 } & Pre-obese / Obese $(>23)$ & $3(5.3 \%)$ \\
\hline \multirow{2}{*}{ Adverse drug reactions } & Present & $29(52.6 \%)$ \\
\cline { 2 - 3 } & Absent & $26(47.4 \%)$ \\
\hline \multirow{2}{*}{ Substance abuse } & Alcohol & $17(31.6 \%)$ \\
\cline { 2 - 3 } & Smoking & $15(26.3 \%)$ \\
\hline \multirow{4}{*}{ Treatment outcomes } & Cured & $5(74.5 \%)$ \\
\cline { 2 - 3 } & Lost to follow-up & $0(1 \%)$ \\
\cline { 2 - 3 } & Failure & $6(10.9 \%)$ \\
\cline { 2 - 3 } & Death & $3(5.5 \%)$ \\
\cline { 2 - 3 } & Continuing & \\
\hline
\end{tabular}


Table 1 depicts the clinical and treatment characteristics of the study patients. A total of 55 patients who fulfilled the study criteria participated in the study. Their average age was $38 \pm 3.6$ years. Most of the patients (70.9\%) had low body mass index. Alcohol consumption and smoking were reported by $31.6 \%$ and $26.3 \%$ of patients respectively. A majority of $74.5 \%$ of patients got successfully cured at the end of treatment, whereas $9.1 \%$ of patients were lost to follow-up and 10.9\% deaths were also reported. There were no cases of failure of treatment in the study. Adverse drug reactions were reported among $52.6 \%$ of the patients. The definitions of the various adverse drug reactions are mentioned in the Table 2.

Table 2: Definition of adverse events:(11)

\begin{tabular}{|l|l|}
\hline \multicolumn{1}{|c|}{ Adverse events } & \multicolumn{1}{c|}{ Definitions } \\
\hline Ototoxicity & $\begin{array}{l}\text { Tinnitus, hearing loss confirmed by physical examination } \\
\text { or audiometry, presence of disequilibrium }\end{array}$ \\
\hline Hypokalemia & At least one serum potassium value <3.5 mmol/l \\
\hline $\begin{array}{l}\text { Central nervous } \\
\text { system disorders }\end{array}$ & $\begin{array}{l}\text { Headache, dizziness and seizure activity as reported by } \\
\text { patient or witness }\end{array}$ \\
\hline Peripheral neuropathy & $\begin{array}{l}\text { Numbness, weakness, tingling, burning/pain in the } \\
\text { extremities, diagnosed by physician or electromyography }\end{array}$ \\
\hline Hepatotoxicity & $\begin{array}{l}\text { (1) Elevation of serum transaminases greater than 3 times } \\
\text { of the normal upper limit with symptoms; } \\
\text { (2) elevation of serum bilirubin greater than 2 times of the } \\
\text { normal upper limit with symptoms; } \\
\text { (3) elevation of serum transaminases or serum bilirubin } \\
\text { greater than 5 times of the normal upper limit with or } \\
\text { without symptoms }\end{array}$ \\
\hline Nephrotoxicity & $\begin{array}{l}\text { Elevation of at least one serum creatinine value greater } \\
\text { than 133umol/l }\end{array}$ \\
\hline Psychiatric disorders & $\begin{array}{l}\text { Presence of depression, anxiety, psychosis, suicide, } \\
\text { nightmares and convulsion }\end{array}$ \\
\hline Arthralgia & $\begin{array}{l}\text { Elevated uric acid, or with pain, swelling or stiffness in } \\
\text { the joints reported by patients }\end{array}$ \\
\hline $\begin{array}{l}\text { Gastrointestinal } \\
\text { disorders }\end{array}$ & $\begin{array}{l}\text { Presence of nausea, vomiting, anorexia, abdominal pain, } \\
\text { diarrhea, epigastric discomfort, hematemesis, melena, } \\
\text { positive endoscopic findings }\end{array}$ \\
\hline Hypothyroidism & $\begin{array}{l}\text { At least one measure of serum thyroid stimulating } \\
\text { hormone greater than the normal upper limit }\end{array}$ \\
\hline Visual impairment & $\begin{array}{l}\text { Presence of visual changes, including vision loss, pain on } \\
\text { moving the eye Decrease }\end{array}$ \\
\hline $\begin{array}{l}\text { Hematologic } \\
\text { disorders }\end{array}$ & $\begin{array}{l}\text { Decrease of hemoglobin, leukocyte or platelet count to } \\
\text { less than the normal lower limit }\end{array}$ \\
\hline
\end{tabular}

Table 3 describes the details of the various adverse drug reactions observed during the anti-tubercular therapy. In the intensive phase, gastro-intestinal intolerance (49.1\%) was the most common ADR reported, followed by dizziness $(38.2 \%)$, psychiatry symptoms of depression (10.9\%) and arthralgia $(9.1 \%)$. A $7.3 \%$ of patients had developed hepatotoxicity. There was one case each (1.8\%) of anemia, ototoxicity, nephrotoxicity, cerebrovascular accident with monoparesis and seizures reported in the study (Table 3). In the continuation phase, psychiatric symptoms (41.8\%) were the most common ADRs observed, with depression seen in $36.4 \%$ and suicidal tendencies seen in $5.5 \%$ of patients. A $18.2 \%$ of patients had gastro-intestinal intolerance. Also, there were $3(5.5 \%)$ cases of peripheral neurpathy, $4(7.3 \%)$ cases of dizziness and $1(1.8 \%)$ case of anemia reported during this continuation phase (Table 3).

Table 3: Distribution of adverse drug reactions among the patients

\begin{tabular}{|l|c|c|}
\hline \multicolumn{1}{|c|}{ Adverse drugs reactions } & $\begin{array}{c}\text { During IP } \\
\text { (Total number of } \\
\text { patients N=55) }\end{array}$ & $\begin{array}{c}\text { During CP } \\
\text { (Total number of } \\
\text { patients N=55) }\end{array}$ \\
\hline Gastro intestinal intolerance & $27(49.1 \%)$ & $10(18.2 \%)$ \\
\hline Dizziness & $21(38.2 \%)$ & $4(7.3 \%)$ \\
\hline Hepatotoxicity & $4(7.3 \%)$ & $0(0)$ \\
\hline
\end{tabular}




\begin{tabular}{|l|c|c|}
\hline Arthralgia / Joint pains & $5(9.1 \%)$ & $0(0)$ \\
\hline Nephrotoxixity & $1(1.8 \%)$ & $0(0)$ \\
\hline Ototoxicity & $1(1.8 \%)$ & $0(0)$ \\
\hline Anemia & $1(1.8 \%)$ & $1(1.8 \%)$ \\
\hline Psychiatric Symptoms & $6(10.9 \%)$ & $20(36.4 \%)$ \\
\hline Depression & $0(0)$ & $3(5.5 \%)$ \\
\hline Suicidal tendencies & $6(10.9 \%)$ & $23(41.8 \%)$ \\
\hline Psychiaric symptoms total & $3(5.5 \%)$ & $3(5.5 \%)$ \\
\hline Neurological Disorders & $0(0)$ \\
\hline Peripheral neuropathy & $1(1.8 \%)$ & $0(0)$ \\
\hline CVA with Monoparesis & $1(1.8 \%)$ & \\
\hline Seizures &
\end{tabular}

Note: Multiple responses possible

Table 4 shows the details of the various co-morbidities in relation to the adverse drug reactions. A majority of patients who reported ADRs (86.2\%) were underweight (BMI $<18.5 \mathrm{Kg} / \mathrm{mt}^{2}$, Fig. 1). Low Body Mass Index $\left(<18.5 \mathrm{Kg} / \mathrm{mt}^{2}\right)$ was found to be significantly associated with occurrence of adverse drug reactions. Other comorbidities observed were hypertension $(9.1 \%)$, diabetes mellitus $(5.5 \%)$, once case each $(1.8 \%)$ of venous thrombosis and sexually transmitted disease (STD)

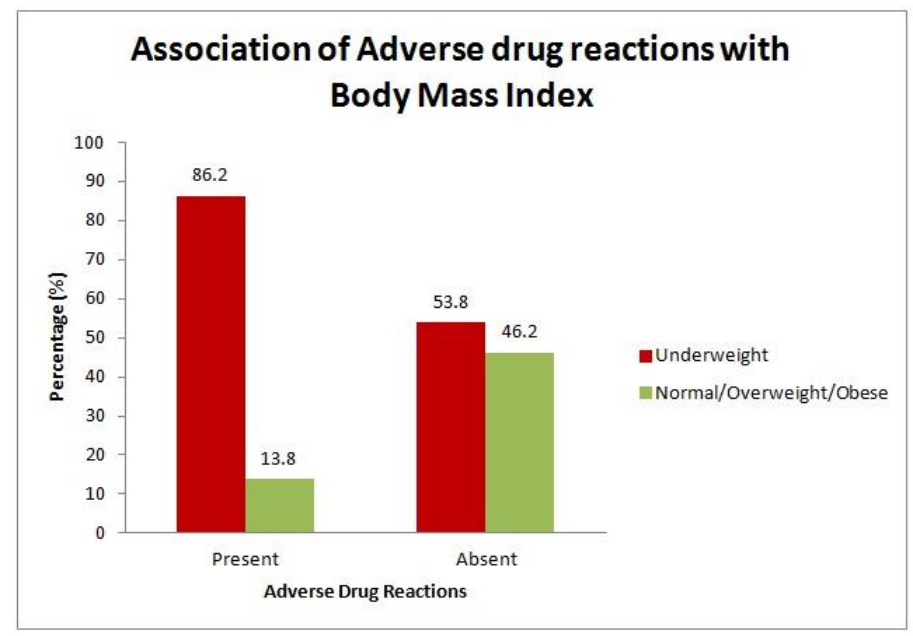

Fig. 1: Association of adverse drug reactions with body mass index

Table 4: Association of co-morbidities with adverse drug reactions among DR-TB patients

\begin{tabular}{|c|c|c|c|c|}
\hline \multirow[b]{2}{*}{$\begin{array}{l}\text { Co-morbidities among } \\
\text { the MDR TB patients }\end{array}$} & \multicolumn{2}{|c|}{ Adverse drug reactions } & \multirow{2}{*}{$\begin{array}{c}\text { Total DR-TB } \\
\text { patients } \\
\mathrm{N}=55(\%)\end{array}$} & \multirow[b]{2}{*}{$p$ value } \\
\hline & $\begin{array}{c}\text { Present } \\
\mathbf{n}=29(\%)\end{array}$ & $\begin{array}{c}\text { Absent } \\
\mathrm{n}=26(\%)\end{array}$ & & \\
\hline $\begin{array}{l}\text { Underweight (BMI: } \\
\left.<18.5 \mathrm{Kg} / \mathrm{mt}^{2}\right)\end{array}$ & $27(86.2 \%)$ & $12(53.8 \%)$ & $39(70.9 \%)$ & $\begin{array}{l}\mathrm{p}< \\
0.05^{*}\end{array}$ \\
\hline Diabetes mellitus & $2(6.9 \%)$ & $1(3.8 \%)$ & $3(5.5 \%)$ & $p>0.05$ \\
\hline Hypertension & $3(10.3 \%)$ & $2(7.7 \%)$ & $5(9.1 \%)$ & $p>0.05$ \\
\hline Venous thrombosis & $0(0)$ & $1(3.8 \%)$ & $1(1.8 \%)$ & $p>0.05$ \\
\hline STD & $1(1.8 \%)$ & $0(0)$ & $1(1.8 \%)$ & $p>0.05$ \\
\hline
\end{tabular}

Chi square test applied. *p value $:<0.05$ - significant association

\section{Discussion}

For a developing country like India, the emergence at an alarming rate of drug resistant tuberculosis has led to various clinical, social and financial implications, furthermore posing a major threat to the effective TB control[1,3-5]. The antitubercular drugs used in Cat IV regimen of RNTCP have high propensity to cause adverse drug reactions. These ADR's have to be effectively managed, so as to prevent the rise in the rates of non-adherence to treatment, default rates, which will go a long way in reducing the associated morbidity and mortality[1,4-6]. The present study was conducted among the drug resistant tuberculosis 
patients reporting at our tertiary level teaching hospital situated in south India.

In this study, the drug resistant $\mathrm{TB}$ was predominantly high among the productive age group (average age among DR-TB patients: $40 \pm 3.6$ years), male gender $(80.0 \%)$ and underweight patients $(70.9 \%)$ which is comparable with the findings of the studies done elsewhere in India[4,5,7-10]. The high proportion of DR-TB among economically productive age group and among males, could be possibly be due to the presence of habits such as smoking $(26.3 \%)$ and alcohol consumption (31.6\%), high risk-taking behaviour, ignorance, more out-door activities and social contacts[4,5,8-11]. Additionally, gender disparity for disease reporting, social stigma/ cultural barriers which impair the access of females to health care facilities could also have been the possible reasons for the gender differences[4,5,8-11]. On the contrary, Waghmare MA et al., in their study conducted in a tertiary care health centre in Mumbai, found high female predominance of DR-TB, which they attributed to high nutritional deficiencies prevalent among females (Table 1)[12].

A majority of the three fourth $(74.5 \%)$ of the DRTB patients were 'cured' at the end of the Cat IV regimen in our study (Table 1). A Cure rate $61 \%$ was reported in the study conducted by Singhla $\mathrm{R}$ et al[13]. Other studies have reported a cure rate of $31.8 \%$ $55 \%[5,8,14,15]$. The high percentage of favourable outcome (cure rates) of the present study can be attributed to strict adherence to treatment guidelines, public private partnership model of RNTCP, effective management of adverse drug reactions as per the RNTCP guidelines, periodic and effective patient counselling, meticulous and regular follow-ups $[1,16]$.

Gastrointestinal disturbances (nausea, vominting, diarrhea) were the most common adverse reactions reported in the present study. Almost half of the DR-TB patients $(49.1 \%)$ suffered from this ADR in the intensive phase (Table 3). The milder cases of GI disturbances were managed symptomatically coupled with reassurance \& continuation of treatment with $\mathrm{H} 2$ antagonist/proton-pump inhibitor and antiemetics helped to improve compliance. Cycloserine was stopped in one patient because of severe gastro intestinal intolerance. The drug was replaced with PAS (para-amino salysilic acid) which was well tolerated. Cycloserine and ethionamide were stopped in another patient due to severe gastro intestinal intolerance. Cycloserine was replaced with PAS for this patient, but the drug was not tolerated well. This aspect was discussed with World Health Organization (WHO) consultant for TB, who suggested initiating Tab Linezolid and Tab Clofazimine, according to the PMDT 2017 guidelines and these drugs were well tolerated[1]. there was reduction in the proportion of GI disturbances in the continuation phase (18.2\%) seen in Continuation Phase (Table 3). Similar results are reported in the studies conducted by Awad NT et al., and Rathod KB et al $[10,17]$.

Dizziness $(38.2 \%)$, arthralgia $(9.1 \%)$, hepatotoxicity $(7.3 \%)$ and neuropathy $(5.5 \%)$ were also reported in the intensive of in the present study (Table $3)$. Nephrotoxicity was observed less frequently in the present study $(1.8 \%)$. Similar results are found in study conducted by Akshata JS et al[18].

Psychiatric adverse effects are known in the treatment of tuberculosis and are associated with increased defaulting and unfavourable prognosis[19]. In our study, the intensive phase recorded a relatively lower proportion of psychiatric symptoms (depression : $10.9 \%$ and nil suicidal symptoms). Whereas, we saw a steep rise in psychiatric symptoms of depression $(36.4 \%)$ and suicidal tendencies $(5.5 \%)$ in the continuation phase (Table 3). Similar rise in the psychiatric symptoms during the $\mathrm{CP}$ of treatment was also observed in study conducted by Patel SV et al., in Central Gujrat[4]. In the present study, Cycloserine and Ethionamide were temporarily withheld in patients with suicidal tendencies after consultation and advice from psychiatrist. The patients who had depression, suicidal tendencies and poor peer support (4 out of 55 patients) were also found to have poor adherence to the treatment. Psychiatrist consultation was taken for these patients and was followed-up with regular counselling.

In one of the patients, cerebrovascular accident with monoparesis was documented. This event started after 3 months of initiation of anti-tubercular therapy. It was an isolated occurrence. The causal relationship of this to ATT could not be established. Patient was referred to neurologist for further evaluation and treatment. Haemoptysis and hypoxia were also reported in few patients (3\% and $2 \%$ respectively). This could have been just a consequence of underlying tuberculosis and not adverse drug reactions. Also, Moxifloxacin drug resistance was found in a male patient aged 50 years, at 21 months of treatment. The drug regiment had to be modified as per the PMDT 2017 guidelines[16].

In order to achieve effective management of DR$\mathrm{TB}$, focus should be on comprehensive interventions including the management of co-morbidities[20]. The most commonly reported co- morbidities like underweight, diabetes mellitus and hypertension. The important aspects which need to be given special attention among the TB patients with comorbidities like DM and HTN are: drug-drug interactions (e.g. rifampicin and oral sulphonylurea derivatives), drugdisease interactions (e.g. peripheral neuropathy induced by both isoniazid and DM), the duration of anti-TB treatment, ensuring adherence to medication and prompt referral and follow-up of patients at diabetic clinics[20,21]. In the present study, hypertension (9.1\%), diabetes mellitus $(5.5 \%)$ were the most common co-morbid conditions found among the patients. Whereas, diabetes mellitus was found to be in 
higher among the DR-TB patients in the studies conducted by Waghmare MA et al., (32.8\%) in Mumbai, Janmeja AK et al. (7.9\%) in Chandigarh[12,15].

In our study, nutritional status was found to be significantly associated with the adverse drug reactions, wherein a high percentage $(86.2 \%)$ of patients reporting adverse drug events were in the underweight category of BMI $<18.5 \mathrm{Kg} / \mathrm{mt}^{2}$ (Table 4). Malnourishment, which is a reflection of low socio-economic status and also symptom of severe disease, requires aggressive intervention[20]. There is scientific evidence of malnutrition being a risk factor for the development of anti-tuberculosis drug adverse reactions[22,23]. A study conducted by Patil SV et al., in Miraj Maharashtra, among DR-TB patients on DOTS plus treated patients also found that higher percentage of patients reporting ADRs were underweight[9]. Nutritional deficiencies inturn may delay recovery by compromising immune functions. Nutritional supplements might therefore promote recovery in people being treated for tuberculosis. Hence, in this regard, the Nikshay Poshan Yojana, started by Central TB Division, Ministry of Health and Family Welfare, is a welcome and much sought after initiative, which is providing nutritional support to the TB patients[22].

\section{Conclusion}

The present study has shown that underweight patients have high propensity for adverse drug reactions. Even though the adverse drug reactions such as GI intolerance and dizziness are most frequent in the intensive phase, psychiatric illnesses of depression and suicidal tendencies are highest in the continuation phase, which might lead to poor treatment adherence. Thus, meticulous and regular follow-ups of the patients with emphasis on early detection of adverse drug reactions during the course of ATT, dosage adjustments to effectively manage the drug reactions and addressing the problem of malnutrition are essential. Furthermore, this study highlights the importance of a regular compulsory psychiatrist opinion as a part of pretreatment evaluation and also during the continuation phase of the antitubercular therapy to detect the emergence of psychiatric symptoms of depression and suicidal tendencies, which will also go a long way in achieving high rates of favourable outcomes among the MDR-TB patients, eventually contributing in realising the the vision for a 'TB-free India' vis-à-vis 'TB-free Globe'.

Conflict of interest: None declared.

\section{Acknowledgement}

The authors express their sincere thanks to the Management of Basaveshwara Medical College \& Hospital, State Task Force of RNTCP Karnataka, Dr. Ranganath R., District Tuberculosis Officer, Chitradurga, Dr.Deepak, WHO consultant for tuberculosis in Karnataka, for providing help and support in conducting the study. We are very thankful to the study participants for their co-operation and active participation without whom, this study would not have been possible.

\section{References}

1. Kanabus A. Information about tuberculosis. TB in India Elimination, Private Care, TB burden, NSPs [Internet]. 2017 [cited 2018 Jul 30]. Available from: https://www.tbfacts.org/tb-india/

2. Sandhu G. Tuberculosis: Current Situation, Challenges and Overview of its Control Programs in India. J Glob Infect Dis 3(2):143-50.

3. Revised National Tuberculosis Control Programe. National strategic plan for tuberculosis elimination 20172025. New Delhi: Mar 2017. 5-56p.

4. World Health Organization . Global Tuberculosis Report 2017. 2017. 5-130 p. Available from: http://www.who.int/tb/publications/global_report/gtbr201 7_main_text.pdf?ua=1

5. Waghmare MA, Utpat K, Joshi JM. Treatment outcomes of drug-resistant pulmonary tuberculosis under programmatic management of multidrug-resistant tuberculosis, at tertiary care center in Mumbai. Med J Dr DY Patil Univ 2017;10(1):41-5.

6. Prasad R, Gupta N, Singh A, Gupta P. Multidrug-resistant and extensively drug-resistant tuberculosis (M/XDR-TB): management in special situations. Int J Med Sci Public Heal [Internet]. 2015;4(12):1626-33.

7. Bharty S, Prakash B, Saraf S, Rai R, Bhatnagar AK, Gupta UA. Initiation of MDR TB treatment : is hospitalization worth ? Indian J Tuberc 2014;61:57-64. Available from: http://tbassnindia.org/images/January_2014_issue.pdf

8. Kapadia VK, Tripathi SB. Adverse drug reactions and outcome analysis of MDR TB patients on DOTS PLUS. Natl J Community Med 2016;7(1):5-9.

9. Patel SV, Bhikhubhai NN, Patel AB, Shringarpure KS, Mehta KG, Shukla LK. Adverse Drug Reactions in Patients put on Multi Drug Resistant Tuberculosis (MDRTB) Treatment in Seven Districts of Central Gujarat. $J$ Young Pharm 2015;7(4):425-31.

10. Revised National Tuberculosis Control Programme. Guidelines on Programmatic Management of Drug Resistant TB ( PMDT ) in India. New Delhi. May 2012. 2-82p.

11. Akshata JS, Chakrabarthy A, Swapna R, Buggi S, Somashekar M. Adverse Drug Reactions in Management of Multi Drug Resistant Tuberculosis in Tertiary Chest Institute. J Tuberc Res 2015;3:27-33.

12. Rathod KB, Borkar MS, Lamb AR, Suryavanshi SL, Surwade GA, Pandey VR. Adverse events among patients of multi drug resistant tuberculosis receiving second line anti TB treatment. Int J Sci Rep 2015;1(6):253-257.

13. Gupta R. Nutritional Assessment and Surveillance of a Community. In: Bhalwar R, Vaidya R, Tilak R, Gupta R, Kunte R, editors. Textbook of Public Health and Community Medicine. 1st ed. Pune: Department of Community Medicine, Armed Forces Medical College, Pune in collaboration with WHO India Office, New Delhi; 2009. p. 788

14. Singh U, Bhushan B, Jhim D, Singh K, Goyal D, Kumar N, et al. Study Profile of Drug-Resistant Tuberculosis at A Northern India Hospital Medical Science. IJSR 2016;5(10):347-50. 
15. Patil SV, Bhagwat RV, Mohite RV, Barphe SS. Profile of adverse drug reactions in multiple drug resistant tuberculosis patients at drug resistant-tuberculosis center Miraj, Maharashtra. 2017;6(5):853-58.

16. Awad N, Nair J, Dhangar G. Adverse Drug Reactions in the Treatment of Drug Resistant Tuberculosis in India. IOSR J Dent Med Sci 2017;16(8):51-4.

17. Rao S. Tuberculosis and patient gender : An analysis and its implications in tuberculosis control. Lung India 2009;26(2):46-7.

18. Singla R, Sarin R, Khalid UK, Mathuria K, Singla N, Jaiswal A, et al. Seven-year DOTS-Plus pilot experience in India : results, constraints and issues. Int J Tuberc Lung Dis 2009;13(8):976-81.

19. Patel SV, Nimavat KB, Alpesh PB, Shukla LK, Shringarpure KS, Mehta KG, et al. Treatment outcome among cases of multidrug-resistant tuberculosis ( MDR TB ) in Western India: A prospective study. $J$ Infect Public Health 2016;9(4):478-84.

20. Janmeja AK, Aggarwal D, Dhillon R. Analysis of treatment outcome in multi-drug resistant tuberculosis patients treated under programmatic conditions. Int J Res Med Sci 2017;5(6):2401-5.
21. Revised National Tuberculosis Control Programme. Guidelines on programmatic management of drugresistant tuberculosis in India 2017. New Delhi. 2017. 1$173 \mathrm{p}$.

22. Bhatt C, KC B. Side effects associated with drugs used in treatment of multi drug resistant tuberculosis and treatment related factors of multi drug resistant tuberculosis patients in Kathmandu valley. SAARC J Tuber Lung Dis HIV/AIDS 2017;14(1):1-6.

23. Kumar A, Kakkar R, Kandpal SD, Sindhwani G. Nutritional status in multi-drug resistance-pulmonary tuberculosis patients. Indian J Community Health 2014;26(2):204-8.

How to cite this article: Sangolli B, Rashmi B. M., Savadi B, Ghodageri S, Sreeharsha. Profile of the adverse drug reactions among the multidrug resistant tuberculosis patients treated at a tertiary level hospital in southern India. Indian J Immunol Respir Med. 2018;3(4):158-164. 